\title{
Human Interleukin-34 facilitates microglia- like cell differentiation and persistent HIV-1 infection in humanized mice
}

\author{
Saumi Mathews ${ }^{1}$, Amanda Branch Woods ${ }^{1}$, Ikumi Katano², Edward Makarov¹, Midhun B. Thomas',
} Howard E. Gendelman', Larisa Y. Poluektova', Mamoru Ito ${ }^{2}$ and Santhi Gorantla ${ }^{1 *}$ (D)

\begin{abstract}
Background: Microglia are the principal innate immune defense cells of the centeral nervous system (CNS) and the target of the human immunodeficiency virus type one (HIV-1). A complete understanding of human microglial biology and function requires the cell's presence in a brain microenvironment. Lack of relevant animal models thus far has also precluded studies of HIV-1 infection. Productive viral infection in brain occurs only in human myeloid linage microglia and perivascular macrophages and requires cells present throughout the brain. Once infected, however, microglia become immune competent serving as sources of cellular neurotoxic factors leading to disrupted brain homeostasis and neurodegeneration.
\end{abstract}

Methods: Herein, we created a humanized bone-marrow chimera producing human "microglia like" cells in NOD.

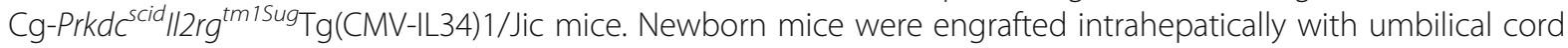
blood derived CD34+ hematopoietic stem progenitor cells (HSPC). After 3 months of stable engraftment, animals were infected with $\mathrm{HIV}-1_{A D A}$, a myeloid-specific tropic viral isolate. Virologic, immune and brain immunohistology were performed on blood, peripheral lymphoid tissues, and brain.

Results: Human interleukin-34 under the control of the cytomegalovirus promoter inserted in NSG mouse strain drove brain reconstitution of HSPC derived peripheral macrophages into microglial-like cells. These human cells expressed canonical human microglial cell markers that included CD14, CD68, CD163, CD11b, ITGB2, CX3CR1, CSFR1, TREM2 and P2RY12. Prior restriction to HIV-1 infection in the rodent brain rested on an inability to reconstitute human microglia. Thus, the natural emergence of these cells from ingressed peripheral macrophages to the brain could allow, for the first time, the study of a CNS viral reservoir. To this end we monitored HIV-1 infection in a rodent brain. Viral RNA and HIV-1p24 antigens were readily observed in infected brain tissues. Deep RNA sequencing of these infected mice and differential expression analysis revealed human-specific molecular signatures representative of antiviral and neuroinflammatory responses.

Conclusions: This humanized microglia mouse reflected human HIV-1 infection in its known principal reservoir and showed the development of disease-specific innate immune inflammatory and neurotoxic responses mirroring what can occur in an infected human brain.

Keywords: Microglia, Hematopoietic stem cells, Humanized mice, HIV-1 infection

\footnotetext{
* Correspondence: sgorantla@unmc.edu

'Department of Pharmacology and Experimental Neuroscience, University of

Nebraska Medical Center, 985880 Nebraska Medical Center, Omaha, NE 68198-5880, USA

Full list of author information is available at the end of the article
}

(c) The Author(s). 2019 Open Access This article is distributed under the terms of the Creative Commons Attribution 4.0 International License (http://creativecommons.org/licenses/by/4.0/), which permits unrestricted use, distribution, and reproduction in any medium, provided you give appropriate credit to the original author(s) and the source, provide a link to the Creative Commons license, and indicate if changes were made. The Creative Commons Public Domain Dedication waiver (http://creativecommons.org/publicdomain/zero/1.0/) applies to the data made available in this article, unless otherwise stated. 


\section{Background}

Human immunodeficiency virus-1 (HIV-1) invades the central nervous system (CNS) early after viral infection [1]. Virus persists in brain despite avid host antiviral cellular and humoral immune responses and during combination antiretroviral therapy (cART) [2]. Low-level viral persistence is associated with neurocognitive dysfunction which is commonplace despite cART. Disease continues to affect up to one third or more of all infected patients [3]. Studies of viral pathogenesis, therapies and the natural history of brain infection remain incomplete based on the available animal models which reflect human disease. There are few ways to replicate virus-induced innate immune responses as they affect neural signaling and neurodegeneration, mostly using in vitro model systems. Indeed, a pressing need remains to develop human disease models of HIV brain infection. This, however, requires the presence of relevant human perivascular macrophages and microglia. Without such cells the ability to represent viral restriction and latency in the nervous system during cART is limited. Humanized mice developed by reconstituting immune compromised mice with human hematolymphoid system have been important tools to study hematopoiesis, cancer, autoimmunity, infections and degenerative disorders [46]. Previously we used humanized mice transplanted with human hematopietic stem cells (HSPC) in NOD/ Scid IL2R $\gamma-/-$ (NSG/NOG) mice to study HIV persistence in brain and its associated neurodegenration [7-10]. However the model proved imperfect and many aspects of human brain infection could not be recapitulated. This was due, in large measure, to the fact that such mice do not have the abilities to reconstitute human microglia following human HSPC transplantation. $\mathrm{Hu}-$ man monocyte-macrophages were found nearly exclusively in meningeal and perivascular areas and very rare are few microglia-like cells located in the parenchyma of the mouse brain $[8,11]$. Moreover, no alterations in such cell ontogeny or robust differentiation of macrophages to microglia were observed even following inflammatory or infectious diseases including HIV-1. Notably, such failures present a critical barrier in progressing studies of HIV-1 brain reservoirs and cure strategies. Nonetheless, the abilities to repopulate a murine brain with functional human microglial-like cells could provide an enormous advantage to study both inflammatory and infectious diseases.

We now posit that the lack of human microglial cells in HSPC reconstituted humanized mice could be due to deficits in species-specific cytokine support. While some cytokines-ligand interactions are cross-reactive between human and mouse, certain interactions are either asymmetric or highly species-specific [12]. Those factors play an important role in macrophage-microglial differentiation are the colony stimulating factor-1 (CSF-1) and interleukin 34 (IL-34) [13]. IL-34 has no sequence similarity with CSF-1 [14]. Although both are the ligands for CSF1 receptor (CSF1R), differentiation of bone marrow (BM)-derived progenitor cells from monocytes to tissue macrophages and dendritic cells require CSF-1. IL-34, in contrast is required specifically for the development of microglia and Langerhans cells [15-17]. The existing immunodeficient transgenic mouse strains that express human CSF-1 $[18,19]$ do not support human microglial development following human HSPC reconstitution (our unpublished observation). Further, multiple mouse strains expressing human CSF-1 including transgenic or knock-in have not reported spontaneous development of microglia [18-21]. To these ends, we developed a human IL-34 (hIL-34) transgenic NOG mice that successfully induced the development of human microglia-like cells seen following human HSPC reconstitution. These microglial-like cells expressed all major myeloid/ microglial cell markers cluster differentiation (CD) 14, CD68, CD163, CD11b, integrin beta 2 (ITGB2), C-X3-C Motif Chemokine Receptor 1 (CX3CR1), CSFR1, triggering Receptor Expressed On Myeloid Cells 2 (Trem2) and Purinergic Receptor P2Y (P2Ry12), and were readily infected by HIV-1. Infection induced human-cell specific molecular events linked to antiviral defense, immune activation and neuroinflammation and reflective to what was previously reported in an infected human host [22-24].

\section{Methods}

Ethics

Animal procedures strictly followed the Institutional Animal Care and Use Committee guidelines approved protocols at University of Nebraska Medical Center (UNMC) (IACUC 18-109) and Institutional Guidelines (11004) approved by the Animal Experimentation Committee of Central Institute of Experimental Animals (CIEA).

\section{Generation of NOG-hIL-34 mice}

NOG (formally, NOD.Cg-Prkdc $c^{\text {scid }} i l 2 g^{\text {tmlSug }} /$ Jic) and NOD/ShiJcl (NOD) were used. NOG mice were maintained in the CIEA under specific-pathogen-free conditions. NOD mice were purchased from CIEA (Tokyo, Japan). To generate the hIL-34 expressing transgenic NOG mouse (NOG-hIL-34), a linearized DNA vector (pCMV6-XL4) containing human IL-34 cDNA (Origene Technologies, Inc., Rockville, MD, USA) under the control of a CMV promoter, was microinjected into fertilized eggs obtained by mating NOG and NOD mice. Out of 26 weaning pups obtained, 3 (\#11, \#13 and \#24) were positive by polymerase chain reactions (PCR) multiplying hIL-34 cDNA. The positive pups were 
further backcrossed to NOG mice to establish NOG-hIL-34 mice. Out of the three lines generated, the line that is highest for the peripheral blood human IL-34 (\#11 with $550 \mathrm{pg} / \mathrm{ml}$ ) was selected to expand the colony. Mice are currently maintained as heterozygous for human IL-34. We did not observe any dectectable abnormalities with growth, shape, size and normal activity. The weight of the mice ranged from 16 to $20 \mathrm{~g}$. Females were smaller than males. The litter size ranged from 5 to 12 pups. They can live over 1.5 years of age without any health issues. Targeted locus amplification (TLA) analyses by Cergentis, Utrecht, Netherlands, was performed to identify the transgene (TG): CMV-XL4-hIL-34 sequence integrated sites in the mouse genome, break point sequences between TG and genome, genetic variations of the TG and to assess the structural variants around the transgene. Bone marrow cells were used and processed for TLA and sequencing [25], using two primer sets 1. ACTAATGACCCCGTAATTGA and GTCA ATGACGGTAAATGGC, and 2. TTTGTGATGCTCGT CAGG and GCAGATTACGCGCAGAAA.

\section{Human IL-34 quantitation by ELISA}

Transgenic expression of hIL-34 was evaluated by quantifying hIL-34 in mouse plasma (1:10 dilution) from NOG-hIL-34 $(n=6)$. NOG control $(n=5)$ were included in the assay to serve as negative controls. hIL-34 was quantified using human IL-34 ELISA Quantitation set (R\&D systems, MN, USA) as per the manufacturer's instructions. Absorbance was read at $450 \mathrm{~nm}$ on a SpectraMax M3 (Molecular Devices, USA). The hIL-34 ELISA kit sensitivity was low with high background. 1:10 dilution of plasma was used for the assay. Some samples were excluded because of lack of detection due to higher dilution used with sample availability.

\section{RT-PCR for hIL-34 transcripts}

RNA from spleen, lung, liver, kidney, skin and brain tissues was obtained by homogenizing in Trizol solution using a Qiagen Tissue Lyzer II (Valencia, CA, USA) and isolating RNA by phenol-chloroform method. cDNA was synthesized from RNA using Verso cDNA Synthesis Kit (Thermo Scientific, Vilnius, Lithuania) as per manufacturer's instructions. Real-time PCR amplification was performed on the ABI Step One Plus machine (Applied Biosystems, MA, USA) using TaqMan detection chemistry. We compared the expression of hIL-34 (Hs01050926_m1) in CD34-NOG-hIL-34 mouse samples against NOG mouse samples. Mouse IL-34 was also assayed using Mm01243248_m1 primer/probe set. GAPDH (Mm99999915_g1) was used as housekeeping gene. The real-time PCR settings were as follows: $50{ }^{\circ} \mathrm{C}$ for $2 \mathrm{~min}, 95^{\circ} \mathrm{C}$ for $10 \mathrm{~min}, 40$ cycles of $95^{\circ} \mathrm{C}$ for $15 \mathrm{~s}$, and $60^{\circ} \mathrm{C}$ for $1 \mathrm{~min}$. The fold change of the target gene expression relative to GAPDH was determined in the transgenic group and the control group. This was performed by using threshold cycle $\left(\mathrm{C}_{\mathrm{T}}\right)$ and the $2^{-\Delta \Delta C T}$ method, where $\Delta \mathrm{C}_{\mathrm{T}}=\mathrm{C}_{\mathrm{T}}$ IL34- $\mathrm{C}_{\mathrm{T}}$ GAPDH and $\Delta \Delta \mathrm{C}_{\mathrm{T}}=$ $\Delta \mathrm{C}_{\mathrm{T}}$ transgenic $-\Delta \mathrm{C}_{\mathrm{T}}$ control. Human IL-34 expression was analyzed in tissues from 17 NOG-hIL-34 mice, except for skin $(n=5)$, and compare with NOG controls $(\mathrm{n}=5)$.

\section{Human CD34+ HSPC isolation}

Human CD34+ HSPC were obtained from human cord blood of healthy full-term newborns after getting parental written informed consent and approval from Institutional Review Board of UNMC (Department of Gynecology and Obstetrics). After density gradient centrifugation of cord blood in leukocyte separation medium (MP Biomedicals, Santa Ana, CA, USA) at 300 g for $35 \mathrm{~min}$, the buffy coat was collected for enriching $\mathrm{CD}_{3}{ }^{+}$cells using immunomagnetic beads according to the manufacturer's instructions $\left(\mathrm{CD} 4^{+}\right.$selection kit; Miltenyi Biotec Inc., Auburn, CA). Purity of isolated $\mathrm{CD}_{3} 4^{+}$cells was evaluated by flow cytometry. CD $34^{+}$ HSPCs were either used fresh or stored in liquid nitrogen using freezing medium with $50 \%$ Bovine serum albumin (Sigma-Aldrich, St Louis, MO, USA), 40\% Iscove'smodified Dulbeccos's medium (GIBCO, Life technologies, Carlsbad, CA, USA) and 10\% dimethyl sulfoxide (DMSO; Sigma-Aldrich, St Louis, MO, USA).

\section{Human $\mathrm{CD}_{3} 4^{+} \mathrm{HSPC}$ transplantation}

NOG-hIL-34 mice were bred and housed in the pathogen-free facility at the UNMC. New born pups (post-natal day 0-1) were irradiated with 1 Gy (RS 2000 X-ray Irradiator, Rad Source Technologies, Inc., Suwanee, GA, USA). After $4 \mathrm{~h}$ of irradiation, pups were intrahepatically injected with $10^{5} \mathrm{CD} 4^{+}$HSPCs. A total of 17 reconstituted animals were used in the study. For comparison, NSG (NOD.Cg-Prkdc $c^{\text {scid }} I l 2 \mathrm{rg}^{t m 1 W^{K j l}} / \mathrm{Sz}$, Stock no.:005557 from Jackson laboratories) mice were also reconstituted with $\mathrm{CD} 34^{+}$HSPCs. Engraftment of human leukocytes were examined by flow cytometry analysis of blood samples collected from the facial vein after 12 weeks post-engraftment.

\section{Flow cytometry}

Blood samples were collected from a facial vein or by direct heart puncture after euthanasia in ethylene diamine tetraacetic acid (EDTA)-containing tubes (BD Microtainer, Franklin Lakes, NJ, USA) and centrifuged at $1800 \mathrm{rpm}$ for $8 \mathrm{~min}$. Splenocytes were collected by crushing the spleen tissue through $40 \mu$ cell strainer. Blood cells and splenocytes were reconstituted in a fluorescence activated cell sorting (FACS) buffer (2\% FBS in phosphate-buffered saline) and incubated with a cocktail of antibodies against 
human immune cell markers, CD45+ fluorescein isothiocyanate (FITC), CD3+ Alexa Fluor 700 (AF700), CD19+ Phycoerythrin-Cyanin 5 (PE-Cy5), CD4+ allophycocyanin (APC), CD8+ Brilliant Violet 421 (BV421) and CD14+ Phycoerythrin (PE), for $30 \mathrm{~min}$ at $4{ }^{\circ} \mathrm{C}$. All antibodies and isotype controls were obtained from BD Biosciences, USA. Red blood cells were lysed by FACS lysing solution (BD Biosciences, USA). Stained cells were washed with FACS buffer and fixed with $2 \%$ paraformaldehyde. Data acquisition was carried out with acquisition software FACS Diva v6 (BD Biosciences, USA) in a BD LSR2 flow cytometer, and data were analyzed using FLOWJO analysis software v10.2 (Tree Star, USA). Gates were assigned according to the appropriate control population.

\section{HIV-1 infection}

Mice with established human hemato-lymphoid reconstitution ( $\sim 6-8$ months of age) and positive for IL-34 expression were intraperitoneally infected $(n=$ 12) with the $10^{4}$ tissue culture infectious dose $e_{50}$ $\left(\mathrm{TCID}_{50}\right)$ of macrophage-tropic HIV-1 $1_{\mathrm{ADA}}$ strain. Viral stocks were prepared as described previously [26]. Mice were bled at 3 weeks post infection and euthanized 6 weeks after the infection to collect blood and tissues for analyses.

\section{Measurements of HIV-1 in plasma, spleen and brain}

Viral RNA copies in the mouse plasma, isolated from blood either collected from facial vein bleeding or endpoint cardiocentesis, were determined by using a COBAS Amplicor System v1.5 kit (Roche Molecular Diagnostics, Pleasanton, CA, USA) three and 6 weeks after post infection. Expression of HIV-1 group-specific antigen (gag) RNA in brain were analyzed as described above on the ABI Step One Plus real-time PCR machine (Applied Biosystems, MA, USA) using TaqMan detection chemistry. The primers and probe used for the PCR were: antisense $5^{\prime}$-ATCTGGCCTGGTGCAATAGG-3', sense 5' -ACATCAAGCAGCCATGCAAAAT-3' (Invitrogen, Life technologies, Pittsburgh, PA, USA) and TaqMan probe FAM-CATCAATGAGGAAGCTGCAGAAT GGGATAGA-TAMRA (Applied Biosystems, Foster City, CA, USA). Log fold change expression was calculated using $\Delta \Delta C_{\mathrm{T}}$ method after normalization with an endogenous mouse GAPDH (Mm99999915_g1) transcript expression of total RNA.

\section{Immunohistochemistry}

Tissues (spleen, liver, and left hemisphere of brain) were fixed with $4 \%$ paraformaldehyde for $24 \mathrm{~h}$ at room temperature, and then embedded in paraffin. Antigen retrieval of paraffin-embedded $5-\mu \mathrm{m}$ thick tissue sections were performed with Declere/ trilogy Solution (Sigma-
Aldrich, St Louis, MO, USA) according to the manufacturer's instructions. Immunohistochemistry was performed using EXPOSE Mouse and Rabbit Specific horse radish peroxidase (HRP)/ 3,3'-Diaminobenzidine (DAB) Detection IHC Kit (Abcam, Cambridge, MA, USA) as per manufacturer's instructions. Primary antibodies used were HLA-DQ/DR/DP (CR3/43) (1:100; Novus Biologicals, Littleton, CO, USA), CD14 (EPR3653) (1:500; Abcam, Cambridge, MA, USA), CD68 (KP1) (1:100; Dako, Carpenteria, CA, USA,) CD163 (10D6) (1:100; Thermoscientific, Rockford, IL, USA), P2Ry12 (1:200; Sigma life science, Inc. ST Louis, MO, USA), Iba1 (1:500; Wako life sciences, Richmond, VA, USA) and HIV-1p24 (Kal1) (1:20; Dako, Carpenteria, CA, USA). The nuclei were counterstained with Mayer's hematoxylin. Non-humanized mouse tissues were included in every staining protocol as negative controls for testing the specificity of the antibodies to human proteins. Bright field images were captured and photographed using $20 \times$ and $40 \times$ objectives on a Nuance Multispectral Tissue Imaging system (CRi, Wobum, MA). For quantification, HLA-DR stained sections were scanned using a high-resolution scanner (Ventana Medical Systems, Inc., Oro Valley, AZ, USA). DEFINIENS Tissue Studio $^{\circ}$ software (Definiens AG, Munich, Germany) was used to analyze the brain sections stained for HLA-DR.

\section{RNAScope $^{\oplus}$}

RNAScope $^{\circ}$ (Advanced Cell Diagnostics, Hayward, CA) was performed for the detection of human IL-34 on paraffin embedded sections as per manufacturer's instructions. Briefly, $5 \mu \mathrm{m}$ thick de-paraffinized and dehydrated formalin-fixed paraffin-embedded brain sections were pretreated with hydrogen peroxide at room temperature for $10 \mathrm{~min}$, target retrieval solution for $8 \mathrm{~min}$ at $100^{\circ} \mathrm{C}$ and then protease IV at $40^{\circ} \mathrm{C}$ for $15 \mathrm{~min}$ in a HybEZ hybridization oven. Hybridization with target probe, pre-amplification, amplification, and chromogenic detection using $\mathrm{DAB}$ was carried out as per manufacturer's instructions in HybEZ oven at $40^{\circ} \mathrm{C}$.

For IL-34 RNA detection, a channel 1 anti-sense Hs-IL34-No-XMm, which contains 20 probe pairs targeting 38-1774 of hIL-34 was used in the single-plex chromogenic assay. For morphological detection of HIV RNA copies in spleen and brain tissues, a channel 1 anti-sense HIV-1 Clade B target probe, which contains 78 probe pairs targeting base pairs $854-8291$ of HIV-1 was used. Positive expression was indicated by the presence of brown dots in the infected cells.

\section{Immunofluorescence}

Paraffin embedded five-micron sections were processed and blocked with $10 \%$ normal goat serum with $0.5 \%$ tween 
in $1 \mathrm{X}$ tris buffered saline. Primary antibodies used in the study were mouse (Ms) anti-human HLA- DQ/DR/ DP(CR3/43) (1:100; Novus Biologicals, Littleton, CO, USA), Ms. anti-HIV-1p24 (Kal1) (1:20; Dako, Carpenteria, CA, USA), anti-synaptophysin (YE269) (1:800; Abcam, Cambridge, MA, USA), rabbit (Rb) anti-MAP2 (1:500; Millipore, Burlington, MA, USA), Rb anti-Neurofilament $\mathrm{H}$ (1:400; Millipore, Burlington, MA, USA), Polyclonal Rb anti-glial fibrillary acidic protein (1:1000; Dako, Carpenteria, CA, USA) and Rb anti-Iba1 (1:500; Wako life sciences, Richmond, VA, USA). Secondary antibodies were Alexa Fluor 488-conjugated goat anti-Rb IgG (1:200; Invitrogen, Grand Island, NY, USA) and Alexa Fluor 594conjugated goat anti-ms IgG (1:200; Invitrogen). A Zeiss LSM710 confocal system (Carl Zeiss Microscopy, Jena, Germany) were used for immunofluorescent imaging and images were taken at 63x.

For quantification of the number of human microglial cells, sagittal sections from each mouse $(n=3)$ were double immunostained for Iba1 and HLA-DR. A minimum of 2-4 selected field of views of the same brain region under $400 \times$ magnification were counted for HLA-DR+/Iba1 + (human microglia) and Iba1+ (mouse microglia) using Nuance Multispectral Tissue Imaging system (CRi, Wobum, MA).

\section{Next generation sequencing}

Brain tissues (four uninfected CD34-NOG-hIL-34, four HIV-1-infected CD34-NOG-hIL-34 and four NOG controls) were flash frozen in liquid nitrogen and stored in $-80{ }^{\circ} \mathrm{C}$. Tissue RNA was isolated using Trizol method as described above. RNA was further subjected for RNA cleanup using RNeasy mini columns and DNase is removed using RNase- free DNase set (Qiagen, CA, USA). Nucleic acid integrity was analyzed and the RNA samples were deep sequenced using $100 \mathrm{bp} / \mathrm{read}, \leq 40$ million reads/sample using an Illumina HiSeq 2500 Sequence Analyzer (Illumina, Inc., San Diego, CA, USA). Reads were trimmed using the fqtrim (ccb.jhu.edu/software/ fqtrim/index.shtml) software to remove ambiguous bases from the reads. Quality was assessed for each sample with FASTQC before and after trimming. The reads were aligned with STAR-2.5.3a (https://github.com/alexdobin/STAR) to mouse reference genome, GRCm38.p3, (https://uswest.ensembl.org/index.html) with default parameters, and then were quantified by RSEM 1.2.21 (https://deweylab.github.io/RSEM/), using Ensemble annotations (Additional file 1: Figure S9). The gene and transcript abundance were measured as Transcripts Per Kilobase Million (TPM) values. TPM is calculated by normalizing the gene length, followed by the sequencing depth to make easier comparison of the proportion of reads that mapped to a gene in each sample. The unmapped reads for CD34-NOG-hIL-34 samples were further aligned to human reference genome, GrCh37 (https://uswest.ensembl.org/index.html), using the same pipeline and comparison analysis was performed between uninfected and HIV-1infected samples. The reads that didn't align to human were further aligned to the HIV genome using STAR and quantified by RSEM. Count and expression data were filtered to exclude features aside from protein-coding. This filtered subset of genes was then used to [1] examine the differential expression of various genes between the sample groups in the $\mathrm{R}$ statistical software environment with packages from Bioconductor, [2] identify pathways using Ingenuity pathway analysis (https://www.qiagen-bioinformatics. com). We identified differentially expressed genes with TPM values above 2 and $p$ values $<0.05$. The top ranking upregulated and down regulated genes were selected to plot the graphs. We compared the available literature on genes expressed by microglia and genes differentially expressed in response to HIV infection.

\section{Statistical analysis}

Data was analyzed and plotted using GraphPad prism 7 (Graphpad, USA) and expressed as mean \pm standard error mean (SEM). For transcriptome analysis, the data obtained from was expressed as the mean \pm standard deviation for each group. Student t-test was performed using R/Bioconductor packages. The Benjamini-Hochberg $(\mathrm{BH})$ adjusted $\mathrm{p}$ values were also calculated to adjust for multiple-testing caused false discovery rate (FDR). The $p$-value $<0.05$ was considered to indicate a statistically significant difference.

\section{Results}

Humanized hIL34 transgenic mice

NOD.Cg-Prkd $c^{\text {scid }} I l 2 r g^{\text {tm1Sug }} \mathrm{Tg}$ (CMV-IL34)1/Jic

(NOG-hIL-34), a human IL-34 transgenic mouse model on NOG ${ }^{\mathrm{CIEA}}$ background, was created by inserting a vector containing hIL-34 transgene under the CMV promoter (Fig. 1a). NOG-hIL-34 mice were identified by PCR analysis of ear DNA that amplify hIL-34 (358 bp) transcript (Fig. 1b). TLA analyses showed that transgene was integrated in chr1:25,127,822-25,127,823. No structural rearrangements were found in the host genome around the integration site. (Additional file 1: Figure S1). According to the refseq integration was in intronic region of Adgrb3. RNAseq analyses revealed no alterations in Adgrb3 gene expression between NOG and NOG-hIL-34 mice (data not shown). Human IL-34 expression in mouse tissues including brain was confirmed by ELISA, RT-PCR and RNAScope ${ }^{\bullet}$ analyses (Fig. 1c,d) (Additional file 1: Figure S2). Expression of mouse IL-34 in brain were not significantly different between NOG and NOG-hIL-34 mice. Humanization of NOG-hIL-34 mice (CD34-NOG- hIL-34) followed standard methods 


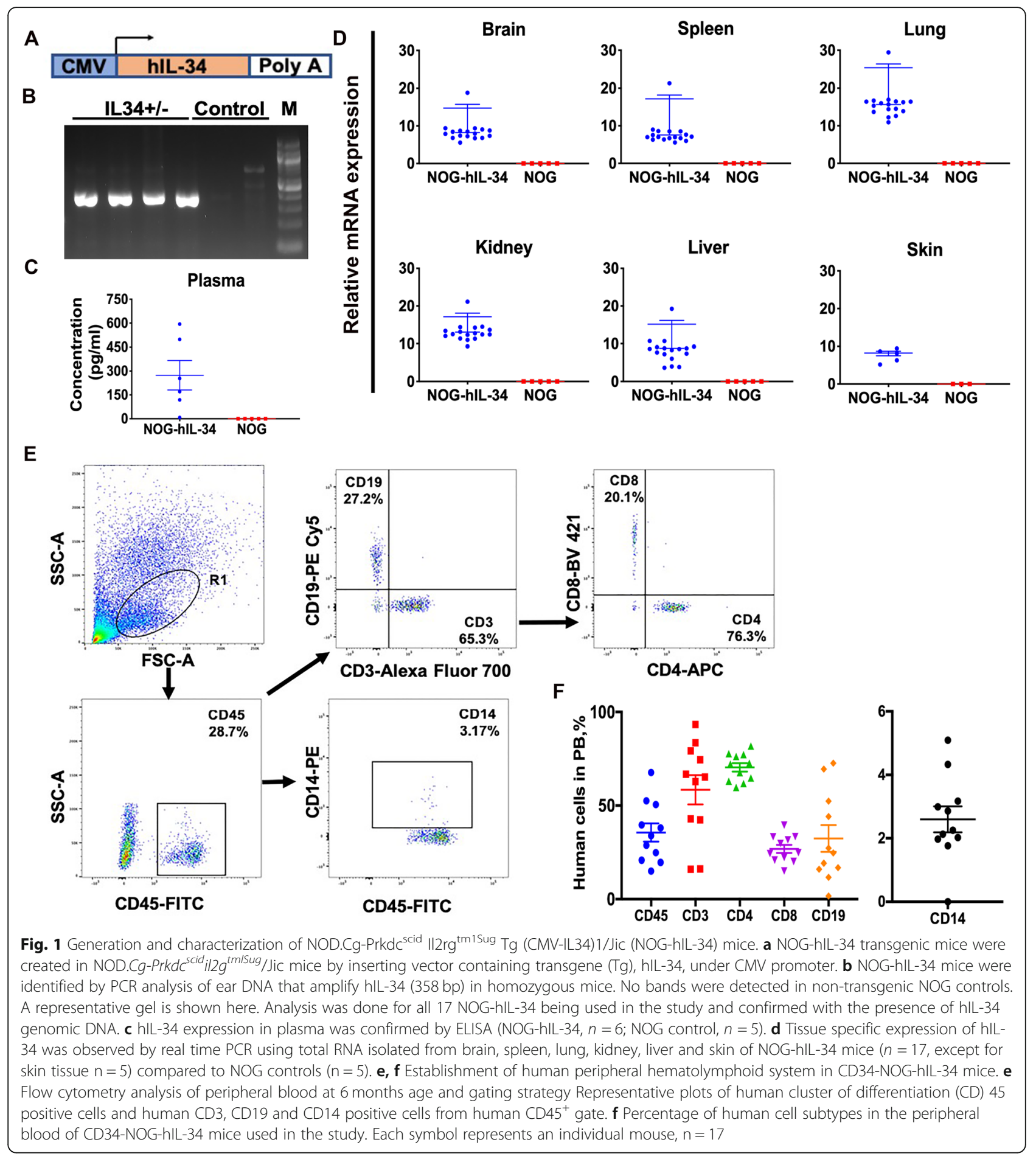

where human $\mathrm{CD}_{3} 4^{+} \mathrm{HSPC}$ are transplanted intrahepatically at birth after conditioning by irradiation [27]. Stable engraftment with human immune system consisting human lymphoid and myeloid cells was achieved in CD34-NOG-hIL-34 mice (Fig. 1e,f), comparable to CD34-NSG (Additional file 1: Figure S3) [28-31]. Such human immune cell reconstitution levels are also similar with other existing humanized mouse models [32]. In CD34-NOG-hIL-34 mice, CD14+ monocyte/macrophages were significantly higher in blood compared to CD34-NSG mice $(0.59 \pm 0.1$ vs $3.1 \pm 0.7, p<0.001)$, however, not as high as in HSPC transplanted human CSF-1, 
CSF2/IL3 and thrombopoietin transgenic mouse model, where human CD33+ myeloid cells were $\sim 60 \%$ of circulating human CD45+ cells [19].

\section{Human microglial-like cells in the hIL-34 trasgenic mouse brain}

We next examined the brains of CD34-NOG-hIL-34 mice for the presence of human cells. Surprisingly, significant numbers of human microglial-like cells were present in the brains of CD34-NOG-hIL-34 mice (Fig. 2a,b) (Additional file 1: Figure S4), compared to CD34-NSG mice, where they were rare or absent. In CD34-NSG mice, human cells are mostly present in meninges, few in perivascular areas and rarely in parenchyma $[8,9,33]$. Tissue human macrophage engraftment was also evident in CD34-NOG-hIL-34 mice, especially with liver Kupffer cells lining sinusoid walls (Fig. 2a). Human microglial-like cells were widely distributed throughout the mouse brain regions in CD34-NOG-hIL-34 mice, with highest presence in olfactory bulb (OB), cortex (CTX), hippocampus (HC), thalamus $(\mathrm{TH})$, substantia nigra $(\mathrm{SN})$ and cerebellum $(\mathrm{CB})$ (Fig. $2 \mathrm{~b}$ and Additional file 1: Figure S4). Microglia mostly with ramified and some with immature compact amoeboid morphology were easily demonstrated (Fig. $2 \mathrm{c}$ ). The presence of human microglial cells was evident from 4 months of age (data shown at 6 months). Percent human microglia from total Iba1+ cell population was determined by counting HLA-DR ${ }^{+} / \mathrm{Ibal}^{+}$double positive human microglia and HLA-DR ${ }^{-} / \mathrm{Ibal}^{+}$mouse microglia. Human microglial reconstitution was up to $80 \%$ of the total microglial population in select brain regions, suggesting that human microglial cells replaced their mouse counterparts (Fig. 2d,e) (Additional file 1: Figure S5). Human microglial interaction with mouse CNS revealed normal astrocyte behavior and neuronal integrity without the signs of phagocytic phenotype of human microglial cells against mouse cells, as determined by lack of colocalization of astrocytic or neuronal staining with HLA-DR+ human microglia (Additional file 1: Figure S6).

\section{Characterization of human microglial-like cells}

The human HLA-DR positive cells in mouse brain not only had microglial morphology, but also positive for myeloid markers CD14, CD163, and CD68. Most importantly, the microglial-like cells populating mouse brain were positive for the putative microglial marker, purinergic receptor P2RY12 (Fig. 3a) [34]. Further, deep sequencing of brain RNA from CD34-NOG-hIL-34 mice and refined search for human genes indicated that a total of 82 human myeloid/monocyte/macrophages/ microglia related genes were expressed by the human cells in CD34-NOG-hIL-34 mice. The highest expression was noted for MHC Class II (CD74) and Class I (B2M).
Expression of the classical macrophage/microglial markers [35], such as AIF1 (IBA1), CD14, CD68, CSF1R, ITGAM (CD11b), P2RY12, CX3CR1, Trem2, TMEM119 were also noted. A spectrum of cytokines and chemokines secreted by microglia were detected, such as chemokine ligand (CCL)-2, tumor necrosis factor (TNF), IL-6, C-X-C motif chemokine ligand (CXCL) 8, IL-8, IL-10, IL-1A, CXCL10 (interferon gamma induced protein 10). The transcription factors PU.1 (SPI 1), ETV5, and apolipoprotein E (APOE) critical for microglial health and function were also found (Fig. 3b) (Additional file 1: Table S2).

\section{HIV-1 infection of the human microglial mouse}

Next, when mice, at 6 months age, were infected with an R5-tropic HIV-1 $1_{\mathrm{ADA}}$ strain injected intraperitoneally, HIV infection was consequently established with viral loads in peripheral blood at $\sim 10^{6}$ RNA copies $/ \mathrm{ml}$ along with infection in secondary lymphoid organs (Fig. 4b) (Additional file 1: Figure S7). A slight depletion of $\mathrm{CD} 4+\mathrm{T}$ cells was observed by 6 weeks of infection as seen in our previous reports $[7-9,28,36]$. Peripheral infection resulted in a robust infection of human microglia which was easily detected (Fig. 4a) (Additional file 1: Figure S8). Infected cells were found throughout the mouse brain regions, with highest levels of infection in $\mathrm{OB}, \mathrm{HC}, \mathrm{TH}$ and CTX. RNAScope technique allowed to see clear infected human cells and extracellular viral particles released from infected cells. Brains of CD34-NOG-hIL-34 mice had 3-4 $\log _{10}$ times $\left(10^{6}\right.$ vs $\left.10^{2}\right)$ higher HIV viral load compared to the CD34-NSG model reconstituted with only human immune system having similar peripheral viral loads (Fig. 4c) (Additional file 1: Table S1). Reactive astrocytes were readily detected, at or near, HIV-1 infected microglia (Fig. 4d).

\section{The HIV-1 infected microglial transcriptome}

Comparison of human specific genes in HIV infected CD34-NOG-hIL-34 mice to uninfected showed a significant downregulation of majority of the transcripts $(62 \%$, 426 genes) among the total differentially expressed genes (687genes) (Fig. 5a, b). The top ranking upregulated and down regulated genes were selected to plot Fig. $5 \mathrm{c}$ and $\mathrm{d}$, respectively. The entire list of genes that were differentially expressed are given in supplementary table for further understanding of the same (Additional file 1: Table S3 and Table S4). Majority of the downregulated genes took part in eukaryotic translation initiation factor 2 (EIF2) signaling whereas upregulated genes were part of interferon signaling (Fig. 5c-f). Most significant human genes upregulated by HIV infection were anti-viral defense genes related to interferon (IFN) pathways such as IFIT1-5, ISG15, MX2, OAS1, OAS2, ISG20 [23, 24]. The other pathways and related genes that were upregulated include pattern recognition receptors and toll-like 

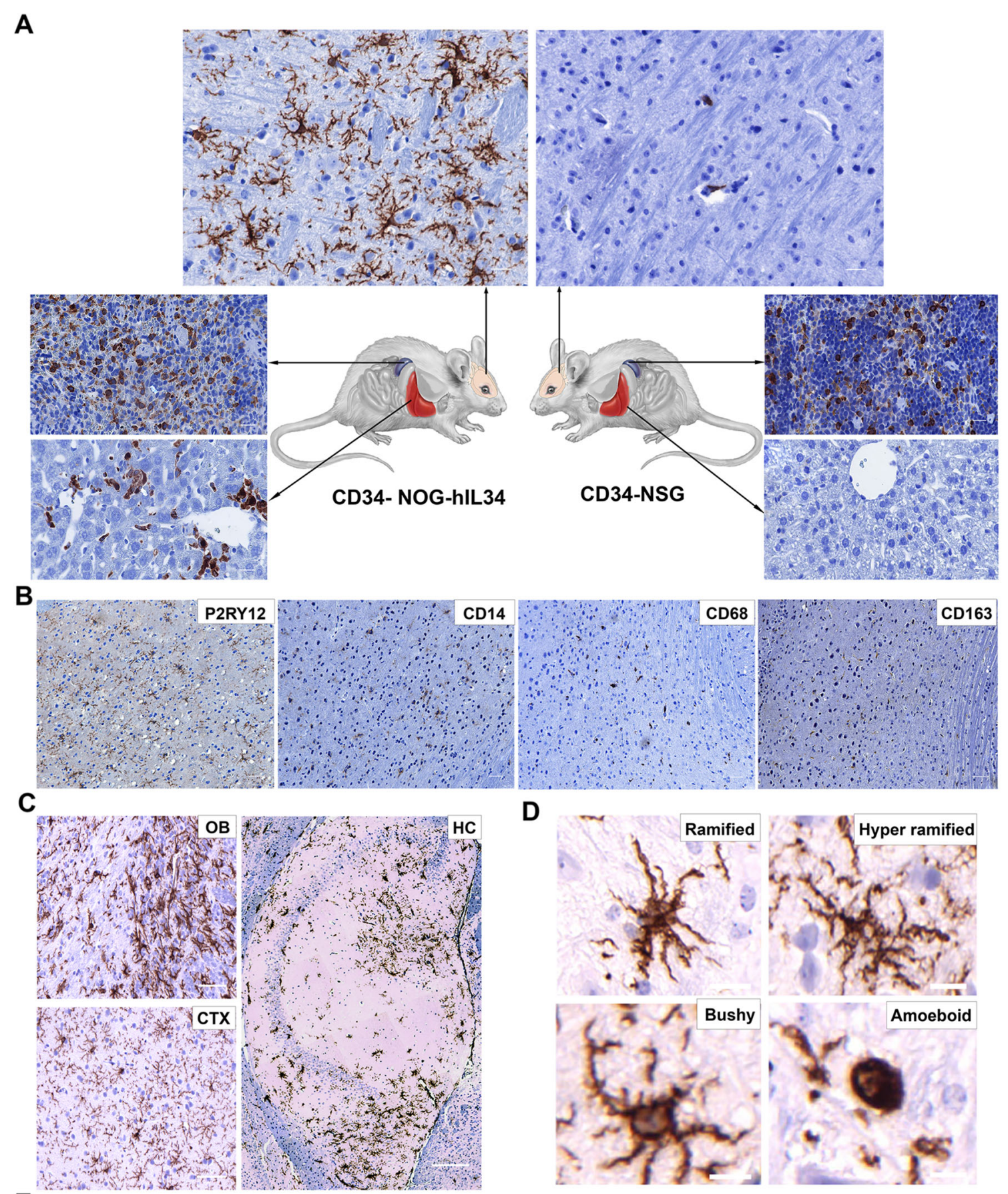

E
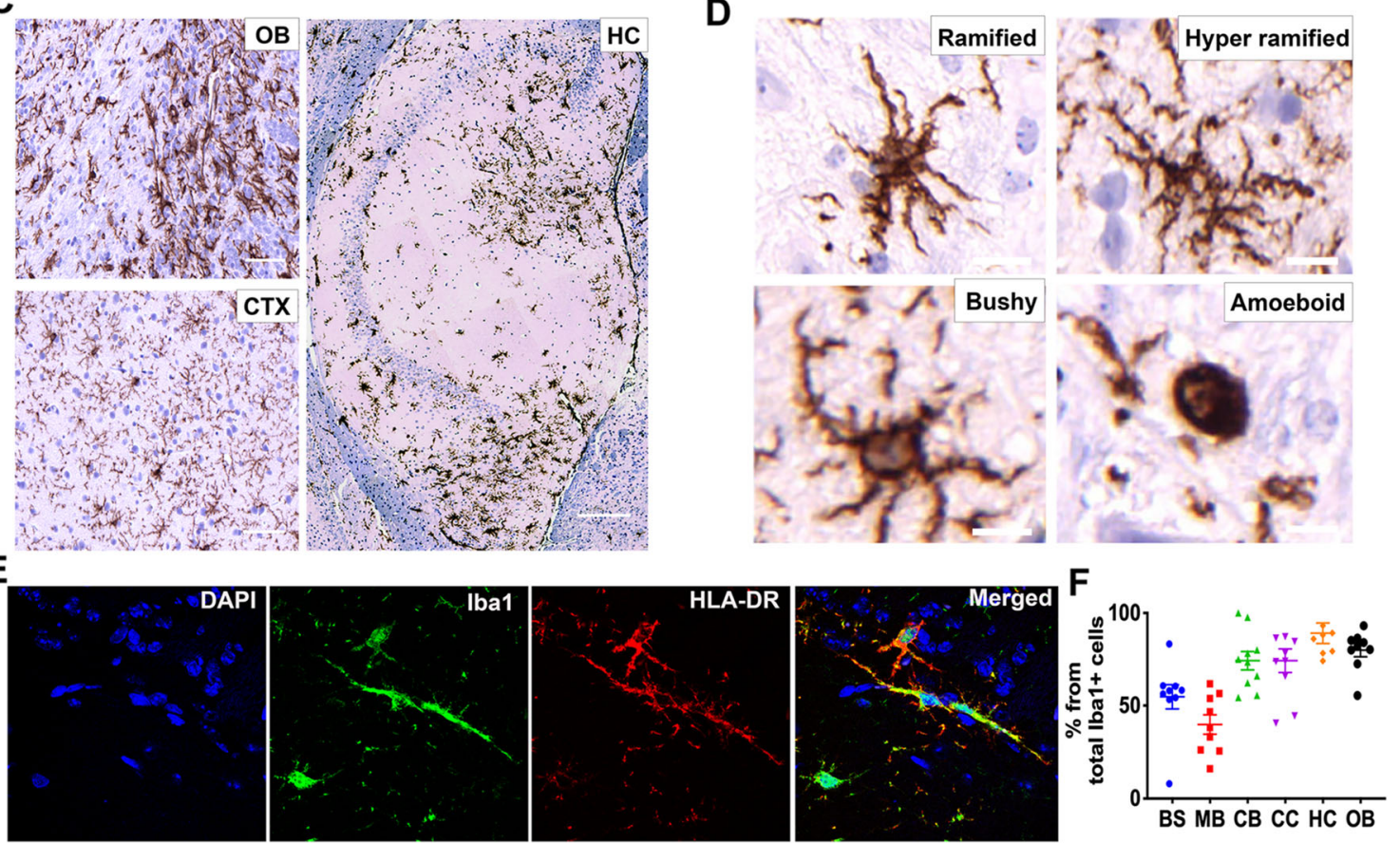

Fig. 2 (See legend on next page.) 
(See figure on previous page.)

Fig. 2 Human microglial-like cells in CD34-NOG-hlL-34 mouse brains. a A comparison of tissue macrophage reconstitution between CD34-NOG-hlL-34 and CD34-NSG mice. Brain sections were stained for HLA-DR, and liver and spleen for human CD68 (Scale bar $10 \mu m$ ). HLA-DR+ human cells were widely distributed in brain parenchyma of CD34-NOG-hlL-34 mice. b Magnified views of olfactory bulb (OB, 20X), cortex (CTX, 20X) and hippocampus (HC, 10X) from CD34-NOG-hlL-34 mouse brain sections stained for HLA-DR. c Microglial morphology of the human cells shown at higher magnification (Scale bar $2 \mu \mathrm{m})$. $\mathbf{d}$ Confocal images of brain stained for HLA-DR and Iba1. e Quantification of HLA-DR/lba1 double positive human microglial cells from total Iba1 positive cells (sample size described in materials and methods, multiple reagions shown on Additional file 1: Figure S5)

receptor (TLR) that recognize viruses (TLR8, IFIH1, MYD88, OAS1,2\&3). The increased expression of TLR8 and myeloid differentiation factor 88 (MYD88) are linked to the activation of NF- $\mathrm{KB}$ transcription factor induced genes (BCL10, IL1RN, IL1B, MALT1) and MAPK (MAPK12) [37]. Mapping the reads from infected CD34-NOG-hIL-34 mice against HIV-1 genome showed significant counts of several HIV-1 genes with gag, nef and env (Fig. $5 \mathrm{~g}$ ), that were not detected previously in CD34-NSG mice brains with human astrocytes and limited infection in brain [10].

\section{Discussion}

We report, for the first time, a human microglial mouse developed from human bone-marrow mouse chimeras, engrafted as newborns intrahepatically with umbilical cord blood derived CD34+ HSPC. Previously, several attempts were reported in reconstituting mouse brain post-natally with HSPC-derived microglia [38-41]. The microglial reconstitution of mouse brain was mostly achieved by the creating a niche by depletion of intrinsic mouse microglia [38], however, these peripherally derived microglial-like cells were distinct in identity from microglia [41]. In HSPC-transplanted humanized mice reconstituted with human hematolymphoid system, there is limited infiltration of human myeloid cells into the mouse brain, mostly in meninges $[8,9,33,42]$. These cells expressed the microglial marker P2RY12, but did not have microglial morphology [43]. Even with high peripheral reconstitution of human myeloid in human CSF-1 transgenic immunodeficient mice, human microglial cells were not reported in mouse brain [19]. Our findings clearly support the fact that hIL-34 was the key player in the human microglial development in
A

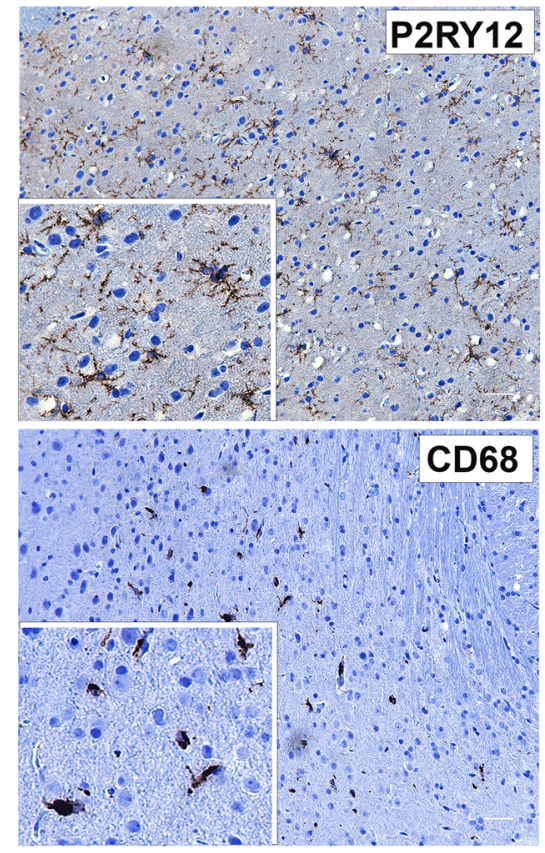

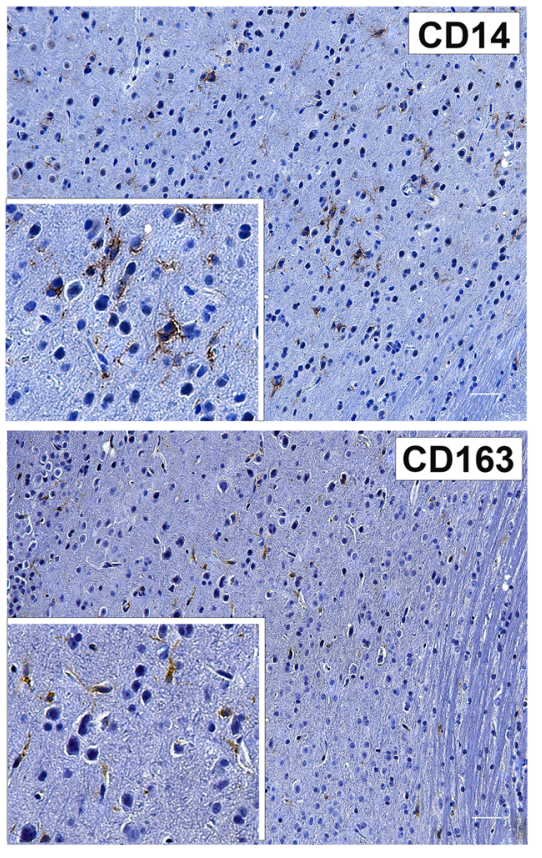

B

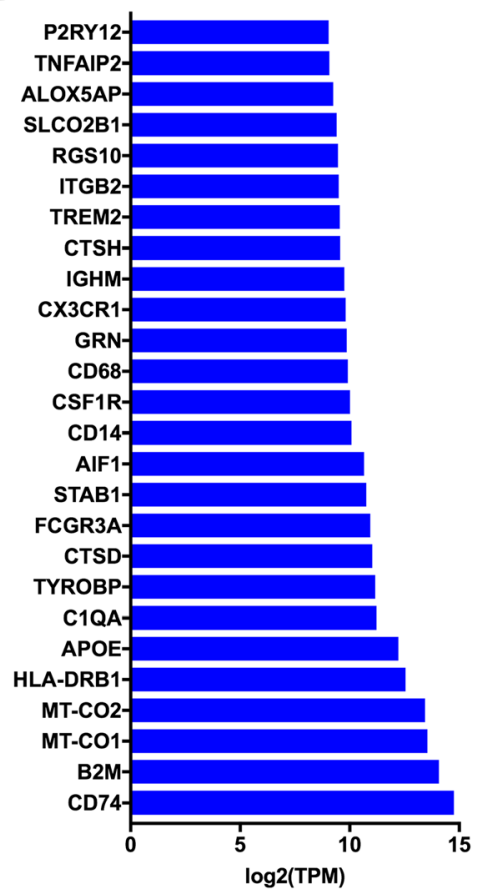

Fig. 3 Expression of microglial markers by the human cells in mouse brain. a Immunohistology of 5 um paraffin embedded CD34-NOG-IL-34 mouse brain sections stained for human microglial markers P2RY12, CD14, CD68 and CD163. Brown cells are positive for the respective protein (Magnification, 200x, Scale bar $20 \mu \mathrm{m}$ ) Inset shows 1000x magnification. b Transcriptomic analysis of RNA extracted from CD34-NOG-IL-34 mice brains by aligning the reads to human genome (h19) showed human myeloid specific gene expression. The graph shows gene names and expression levels of top classical microglial markers in CD34-NOG-hlL-34 mouse brains 


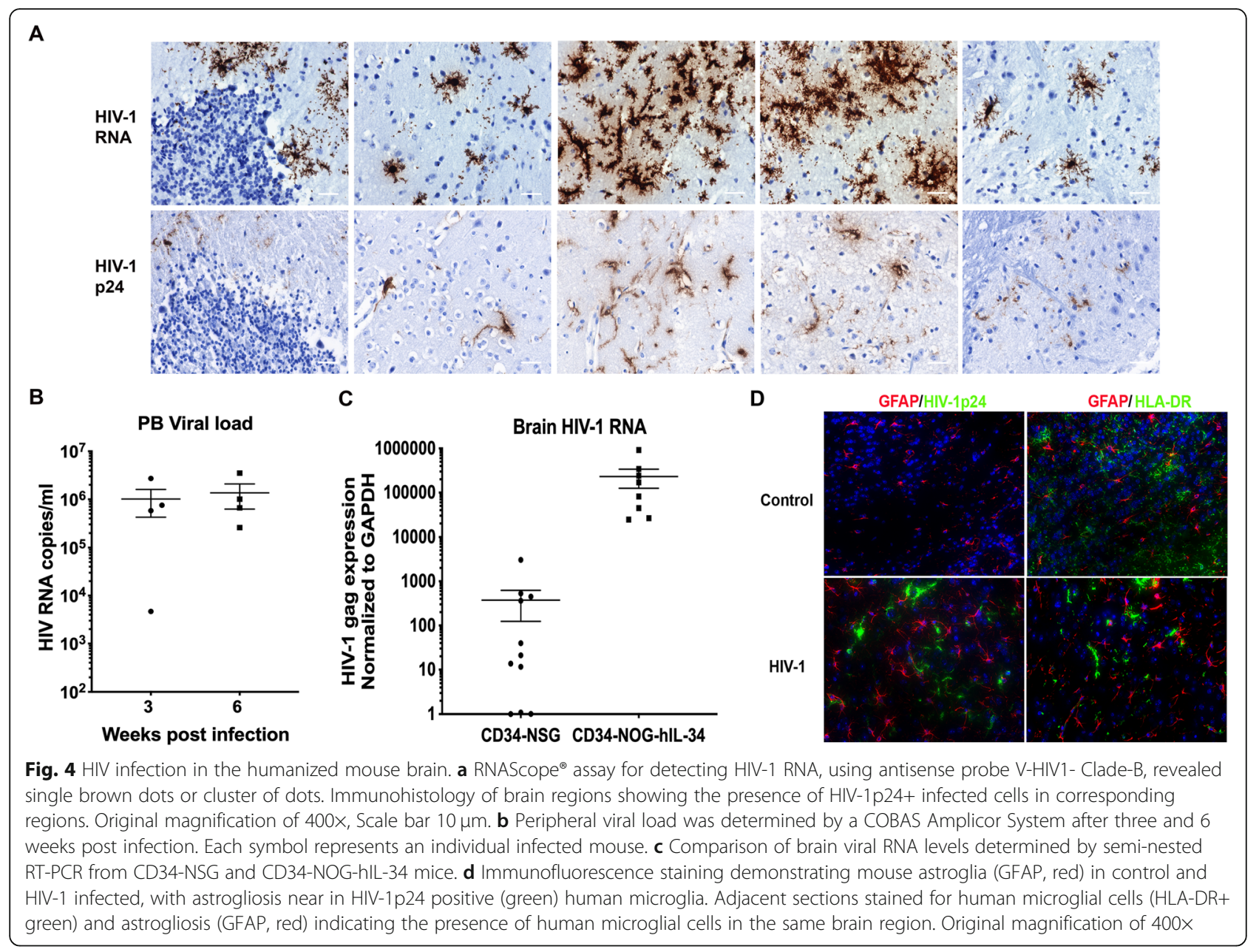

humanized mice. In HSPC transplanted hIL-34 NOG mice, bone marrow-derived monocytes migrated into the mouse brain and differentiated into microglia in presence of human IL-34. Alternatively, human HSPC could also seed the mouse brain very early after transplantation due to conditioning by irradiation and continue to generate human microglial cells in situ [44, 45].

Long-term efforts to reconstitute human microglia in mice have previously attempted with limited success [46]. There are many caveats with the development of microglia form HSPC because of their origin and ontogeny. Microglia are the resident macrophages of the CNS providing developmental support and immune brain protection. The cell's precise origin, ontogeny and identifying markers in human are still remain elusive [47-49]. In adult brain, either in normal or disease state, it is unclear whether the microglia originate solely from cells present in the brain from fetal origins or if there is further input into CNS from HSPC derived myeloid cells [50-52]. While monocytes enter the CNS under steady state and diseased conditions and are transformed into microglial-like cells their "true identity" remains uncertain $[41,50,53]$. Mouse-to- mouse transplant experiments show that donor HSPC can produce microglial-like cells in mice depleted of resident microglia by radiation, chemotherapy, or through cell-specific suicide genes [38, 54]. Microglial ablation scheme using PLX5622, a selective inhibitor of CSF1R, demonstrated that all repopulated microglia were derived from the proliferation of the few surviving microglia [55]. To date, human microglial reconstitution in immune deficient mice was not efficient, regardless of the approach used [46].

IL-34 is not a sole factor responsible for this microglial reconstitution. The regulation of peripheral macrophage ingress into the fetal brain and microglial-like cell differentiation and expansion is facilitated by a gradient of signaling mediators. These include, but are not limited to, matrix metalloproteinases, semaphorins/netrins, monocyte chemoattractant protein-1 (MCP1), macrophage inflammatory protein 1 aplha (MIP-1 $\alpha$ ), ligands of CSF-1R, the fractalkine (CX3CL1)/receptor1 pathway, receptor tyrosine kinase/vascular endothelial growth factor receptor 1 (VEGFR1) interactions, and others [56]. We cannot exclude hIL-34 interactions with the receptor-type 
A

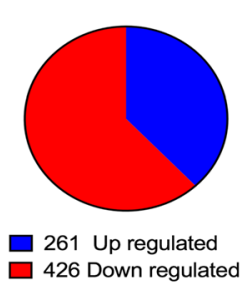

B

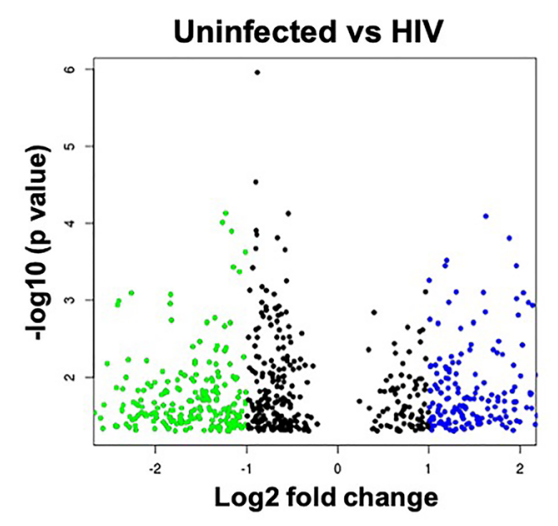

E

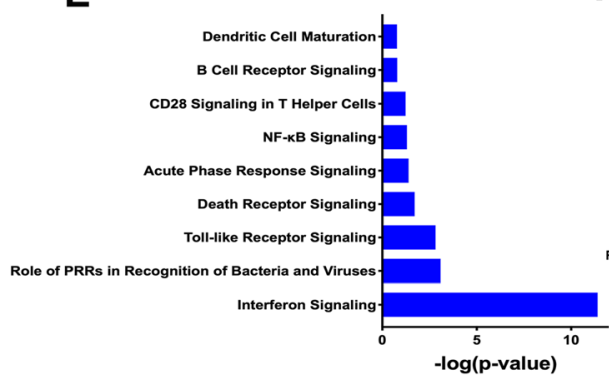

C

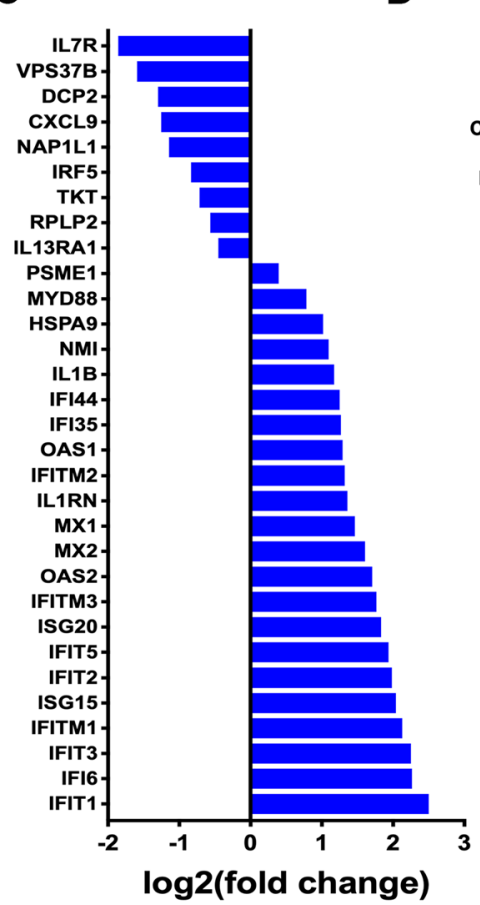

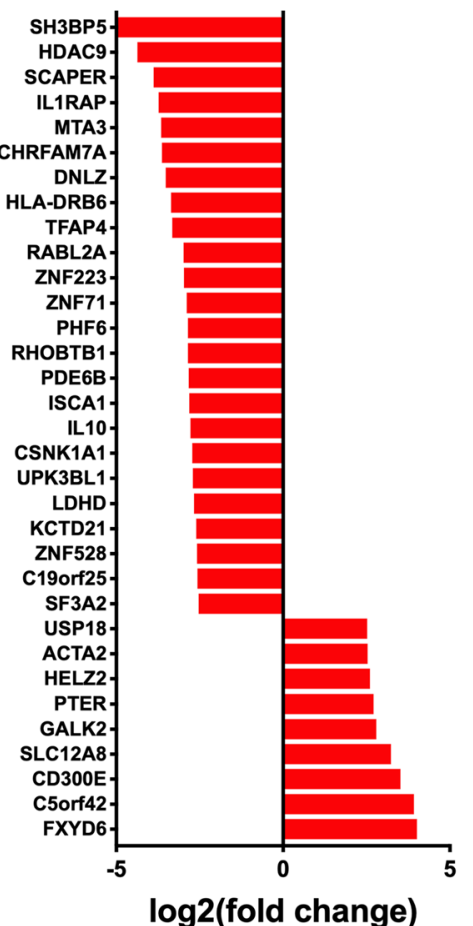

G

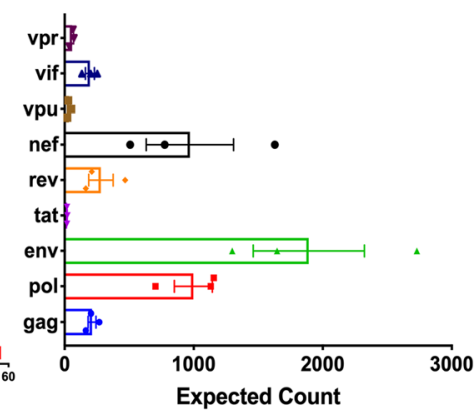

Fig. 5 Transcriptional changes in the brain tissues of CD34-NOG-hIL-34 with HIV-1 infection. a, b Alignment of reads to human genome (h19) comparing uninfected and HIV-1 infected CD34-NOG-IL-34 mice found 687 differentially expressed genes (DEG), and the pie chart (a) and the volcano plot (b) shows the proportion and fold change of upregulated and down-regulated genes, respectively. $\mathbf{c}$, $\mathbf{d}$ Log fold change of top ranking differentially expressed human genes for uninfected vs HIV infected CD34-NOG-hlL-34 mice in human microglia and in brain. e, $\mathbf{f}$ Cellular pathways involving upregulated human genes (261) were related to interferon signaling, PRR and TLR signaling (e), and downregulated human genes (426) were highly associated with pathways of EIF2 signaling and oxidative phosphorylation (f). $\mathbf{g}$ Unmapped reads mapped to HIV-1 ADA genome indicated the expression levels of different HIV-1 genes in infected mouse brain

protein-tyrosine phosphatase zeta (RTPTP- $\zeta)$, a cell surface chondroitin sulfate proteoglycan identified as a second receptor for IL-34, important for cells' ramification [57]. The detailed underlying mechanisms for the successful microglial-like cell reconstitution of mouse brain beyond human IL-34 requires further investigation. Such studies would allow an understanding of what mouse factors influence such brain cell ingress and reconstitution. Adding to such complexities is the fact that human microglial reconstitution in the mouse brain has regional variation. Although human IL34 is constitutively expressed in all cells in the hIL-34 transgenic mice such heterogenous distribution showed high cell density in the hippocampus, olfactory tubercle, basal ganglia, cortex, thalamus and substantia nigra [58]. Regional variation in microglial distribution is also evident in rat and human brains $[59,60]$. In this model human microglia appear to replace mouse microglia. How such "putative" replacement plays a role in brain function is yet to be determined.

Humanized mouse models reconstituted with human hematolymphoid cells have been used to study highly relevant aspects of HIV replication, pathogenesis, therapy, transmission, prevention, and eradication [Reviewed in [4, $61,62]]$. These models were also evaluated for the studies 
of NeuroHIV and brain viral reservoirs [11, 63, 64]. However, lack of human microglia and astrocytes in the mouse brain limits humanized mouse models to study HIV induced brain pathology and to test HIV eradication strategies targeting brain viral reservoirs. Unique humanized mouse models reconstituted with human blood and brain glial cells were developed within our laboratories [10] to mirror human specific antiviral responses that affect HIV brain infections. Human microglia are a major HIV-1 CNS reservoir. We and others explored divergent means to reconstitute the mouse brain with human microglia for studies of HIV-1 infection [8, 42, 43, 65, 66]. Now using hIL-34 transgenic mice, we successfully reconstituted mouse brain with human microglia and established persistent viral infection. Robust infection of microglial cells was observed independent of peripheral infection. It was suggested that peripheral blood monocytes differentiated in presence of IL-34 had increased resistance to HIV-1 infection over macrophage colony stimulating factor (MCSF) derived macrophages [67]. In contrary, both MCSF and IL-34 enhance HIV-1 infection in human microglia in vitro [68]. In SIV infected rhesus macaques IL-34 expression was not increased, unlike MCSF, in macrophages accumulating perivascularly and within the nodular lesions in brains with or without encephalitis. Both MCSF and IL-34 were shown to upregulate CD163 in primary monocytes, a marker for type 2 activation of macrophages [69]. The human microglia in hIL-34 transgenic mouse brain expressed CD163 as detected by both immunohistology and RNAseq analysis, nevertheless, we cannot compare the CD163 expression levels to microglia developed in the absence of IL-34 as there are no microglia in the brains of CD34-NSG mice. The infection in mouse brain was higher in $\mathrm{OB}, \mathrm{HC}, \mathrm{TH}$ and CTX and levels of infection correlated with the higher density of human microglial cells in these regions. In human brain infection is predominantly seen in globus pallidus, substantia nigra and dentate nucleus [70]. Brain imaging studies revealed signs of inflammation and dysmorphology mainly in cortical and subcortical regions, white matter, and basal ganglia deep grey matter. Impairments in memory and hippocampal function, motor deficits with reduced basal ganglia and thalamic volumes were reported [71-74]. HIV infection was also associated with reduced olfactory function with significant decrease in odor identification scores across time [75-77]. Differential gene expression analysis was used to determine the functionality of brain engrafted human microglia in response to HIV infection. The major human cell type in the mouse brain was human microglia, hence, the human genes detected were associated to these cells. There is increased infiltration of human macrophages into the mouse brain mainly in meninges and few in perivascular areas [8], however they are less in number compared to the human microglial cells in the brain parenchyma with infection. We could segregate species-specific responses in our complex human-mouse chimeras [10]. There is a significant increase in the expression of anti-viral defense genes related to interferon signaling (IFI and IFIT families). Toll-like receptor signaling and NF- $\mathrm{kB}$ signaling were also upregulated indicating activation of innate immune response, increased inflammation and immune cell regulation, as host defense mechanisms [7881]. Transcriptomic profiles of the brains of HIV infected patients and SIV infection macaques also displayed significant upregulation of interferon signaling and inflammation related pathways [24, 82-85]. Among down regulated pathways, genes related to eIF2 signaling were affected with HIV infection. Evidence suggests that host cell protein synthesis is modulated during HIV infection and the effect on host protein synthesis can be garnered from the inhibition of PKR induced eIF2 phosphorylation by HIV tat so that the synthesis of the viral proteins occur freely [86, 87]. eIF2 was found affected in patients suffering from neurodegenerative diseases such as Alzheimer's, Parkinson's and Huntington's disease [88]. Further analysis is required to understand the effect of human microglial reconstitution on mouse brain cells and the infection induced neuropathogenesis. In this current study we presented the phenotype of human microglial cells and their response to acute systemic HIV infection. The presence of human microglia and HIV-1 infection showed mild changes in mouse transcriptomics. Further refined analysis of mouse genes is needed to understand the effects of human microglia on neuronal functional and structural changes and deficiencies induced by HIV-1 infection of human cells. Brain pathogenesis assessment require chronic infection, extended analyses and multi-modalities approach as with our previous report using behavior and imaging evaluations [7].

\section{Conclusion}

All together we created a humanized mouse that contained both a human immune system and human brain glial cells. The strength of this model allows it to be used to mimic innate immune activities of the CNS and its interface with peripheral adaptive immunity. The model also offers a template for the studies of HIV-1 infection, neuropathogenesis, therapeutics and potential reservoir sites within the CNS. In this manner the model offers new unchartered opportunities to study disease states of the human brain that were not possible in any past time. Such new opportunities will surely open up pathways towards therapeutics and disease cure strategies.

\section{Additional file}

Additional file 1: Figure S1. Integrated site of the transgene in NOG mouse genome. Figure S2. Human IL-34 expression in different regions of mouse brain. Figure S3. Comparison of human immune cell reconstitution in NSG and NOG-hIL-34 mice. Figure S4. Human microglial 
reconstitution in mouse brain. Figure $\mathbf{S 5}$. Human and mouse glial cell distribution in mouse brain. Figure $\mathbf{S 6}$. Mouse neuronal cell interaction with human microglial cells. Figure S7. Establishment of systemic HIV infection in CD34-NOG-hlL-34 mice. Figure S8. HIV-1 infection in mouse brain. Figure S9. Flowchart of deep sequencing analysis. Table S1. Plasma viral loads of HIV-1 infected humanized NSG mice. Table S2. List of genes expressed by microglia. Table S3. HIV induced transcriptional changes evaluated at 8 months of age (hg19)- Upregulation. Table S4. HIV induced transcriptional changes evaluated at 8 months of age (hg19)- Downregulation. (PDF $1822 \mathrm{~kb}$ )

\section{Abbreviations}

AF: Alexa Fluor; APC: Allophycocyanin; APOE: Apolipoprotein E; BH: Benjamini-Hochberg; BV: Brilliant Violet; CART: Combination anti-retroviral therapy; CB: Cerebellum; CCL: Chemokine ligand; CD: Custer differentiation; CD34-NOG- hIL-34: CD34 cell transplanted NOG-IL-34; CIEA: Central Institute of Experimental Animals; CNS: Central nervous system; CSF-1: Colony stimulating factor-1; CSF1R: CSF1receptor; CTX: Cortex; CX3CL1, VEGFR1, RTPTP-乙: Receptor-type protein-tyrosine phosphatase zeta; CX3CR1: C-X3-C Motif Chemokine Receptor 1; CXCL: C-X-C motif chemokine ligand; DAB: 3,3'Diaminobenzidine; EDTA: Ethylene diamine tetraacetic acid; EIF2: Eukaryotic translation initiation factor 2; FACS: Fluorescence activated cell sorting; FITC: Fluorescein isothiocyanate; HC: Hippocampus; hIL-34: Human IL-34; HIV1: Human Immunodeficiency Virus-1; HRP: Horse radish peroxidase; HSPC: Hematopoietic stem progenitor cells; IFN: Interferon; IL-34: Interleukin34; ITGB2: Integrin Beta 2; MCP-1: Monocyte chemoattractant protein-1; MCSF: Macrophage colony stimulating factor; MIP-1a: Macrophage inflammatory protein 1 aplha; Ms: Mouse; NOG-hlL-34: NOD.Cg-

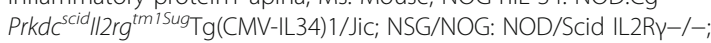
OB: Olfactory bulb; P2RY12: Purinergic Receptor P2Y; PCR: Polymerase chain reaction; PE: Phycoerythrin; Rb: Rabbit; SEM: Standard error of the mean; SN: Substantia Niagra; $\mathrm{TCID}_{50}$ : Tissue Culture Infectious Dose 50; TG: Transgene; TH: Thalamus; TLA: Targetted locus amplification; TLR: Toll like receptor; TNF: Tumor necrosos factor; TPM: Transcripts Per Kilobase Million; Trem2: triggering Receptor Expressed On Myeloid Cells 2; UNMC: University of Nebraska Medical Center

\section{Acknowledgements}

We thank Motohito Goto from CIEA, Victoria Smith and Samantha Wall of the Flow Cytometry research facility, Janice A. Taylor of the Advanced Microscopy Core Facility and Dr. Jiang Jiang of the Tissue sciences facility, Li Wu, Yan Cheng, Sruthi Sravanam, Prasanta Dash, Hang Su, Aditya Bade of Pharmacology and experimental neuroscience at the University of Nebraska Medical Center for technical assistance. Assistance from Catherine L. Gebhart, Technical Director of The Molecular Diagnostics Laboratory, for viral load analysis is noted and appreciated. We also thank Dr. James Eudy, Director of DNA Microarray and Sequencing Core Facilities and Dr. Babu Guda, Director of Bioinformatics for the assistance with RNAseq analyses.

\section{Competing interests}

The authors declare that they have no competing interests.

\section{Funding}

Financial support- NIH/NIDA 5R21DA041018, NIH/OD 5R24OD018546, NIH/ NIA R01 AG043540.

\section{Availability of data and materials}

The data generated during this study is included in this article and its Additional file.

\section{Authors' contributions}

Conceptualization: LYP, SG; Methodology: MI, LYP, SG, SM; Technical assistance: EM, AB, MBT, IK; Validation: SM, LYP, SG; Analysis: SM, SG, HEG; Investigation: SM, LYP, SG; Resources: MI, LYP, SG; Writing - original draft: SM, SG; Writing - review \& editing: LYP, HEG, SG. All authors read and approved the final manuscript.

\section{Ethics approval and consent to participate}

Animal procedures strictly followed the Institutional Animal Care and Use Committee guidelines approved protocols at University of Nebraska Medical
Center (UNMC) (IACUC 18-109) and Institutional Guidelines (11004) approved by the Animal Experimentation Committee of Central Institute of Experimental Animals (CIEA).

\section{Consent for publication}

All authors have read the manuscript and indicated consent for publication.

\section{Publisher's Note}

Springer Nature remains neutral with regard to jurisdictional claims in published maps and institutional affiliations.

\section{Author details}

'Department of Pharmacology and Experimental Neuroscience, University of Nebraska Medical Center, 985880 Nebraska Medical Center, Omaha, NE 68198-5880, USA. ${ }^{2}$ Central Institute for Experimental Animals, Kawasaki-ku, Kawasaki, Japan.

Received: 13 December 2018 Accepted: 12 February 2019

Published online: 05 March 2019

\section{References}

1. Valcour V, Chalermchai T, Sailasuta N, Marovich M, Lerdlum S, Suttichom D, et al. Central nervous system viral invasion and inflammation during acute HIV infection. J Infect Dis. 2012;206(2):275-82.

2. Ko A, Kang G, Hattler JB, Galadima HI, Zhang J, Li Q, et al. Macrophages but not Astrocytes Harbor HIV DNA in the brains of HIV-1 infected Aviremic individuals on suppressive antiretroviral therapy. J Neurolmmune Pharmacol. 2018. https://doi.org/10.1007/s11481-0189809-2.

3. Sutherland EJ, Brew BJ. Human immunodeficiency virus and the nervous system. Neurol Clin. 2018;36(4):751-65.

4. Marsden MD, Zack JA. Humanized mouse models for human immunodeficiency virus infection. Annu Rev Virol. 2017;4(1):393-412.

5. Walsh NC, Kenney LL, Jangalwe S, Aryee KE, Greiner DL, Brehm MA, et al. Humanized mouse models of clinical disease. Annu Rev Pathol. 2017;12: 187-215.

6. Yong KSM, Her Z, Chen Q. Humanized mice as unique tools for humanspecific studies. Arch Immunol Ther Exp. 2018;66(4):245-66.

7. Boska MD, Dash PK, Knibbe J, Epstein AA, Akhter SP, Fields N, et al. Associations between brain microstructures, metabolites, and cognitive deficits during chronic HIV-1 infection of humanized mice. Mol Neurodegener. 2014;9:58.

8. Gorantla S, Makarov E, Finke-Dwyer J, Castanedo A, Holguin A, Gebhart CL, et al. Links between progressive HIV-1 infection of humanized mice and viral neuropathogenesis. Am J Pathol. 2010;177(6):2938-49.

9. Dash PK, Gorantla S, Gendelman HE, Knibbe J, Casale GP, Makarov E, et al. Loss of neuronal integrity during progressive HIV-1 infection of humanized mice. J Neurosci. 2011;31(9):3148-57.

10. Li W, Gorantla S, Gendelman HE, Poluektova LY. Systemic HIV-1 infection produces a unique glial footprint in humanized mouse brains. Dis Model Mech. 2017;10(12):1489-502.

11. Gorantla S, Poluektova L, Gendelman HE. Rodent models for HIV-associated neurocognitive disorders. Trends Neurosci. 2012;35(3):197-208.

12. Scheerlinck, J-PY. Cytokine species specificity and humanized mice. In: Poluektova LY, Garcia JV, Koyanagi Y, Manz MG and Tager AM, editors. Humanized mice for HIV research. New York: Springer; 2014. p. 93-108.

13. Wei S, Nandi S, Chitu V, Yeung YG, Yu W, Huang M, et al. Functional overlap but differential expression of CSF-1 and IL-34 in their CSF-1 receptormediated regulation of myeloid cells. J Leukoc Biol. 2010;88(3):495-505.

14. Garceau V, Smith J, Paton IR, Davey M, Fares MA, Sester DP, et al. Pivotal advance: avian colony-stimulating factor 1 (CSF-1), interleukin-34 (IL-34), and CSF-1 receptor genes and gene products. J Leukoc Biol. 2010;87(5):753-64.

15. Chitu V, Gokhan S, Nandi S, Mehler MF, Stanley ER. Emerging roles for CSF-1 receptor and its ligands in the nervous system. Trends Neurosci. 2016;39(6):378-93.

16. Tong L, Gong Y, Wang P, Hu W, Wang J, Chen Z, et al. Microglia loss contributes to the development of major depression induced by different types of chronic stresses. Neurochem Res. 2017;42(10):2698-711.

17. Baghdadi M, Umeyama Y, Hama N, Kobayashi T, Han N, Wada H, et al. Interleukin-34, a comprehensive review. J Leukoc Biol. 2018;104(5):931-51. 
18. Rathinam C, Poueymirou WT, Rojas J, Murphy AJ, Valenzuela DM, Yancopoulos GD, et al. Efficient differentiation and function of human macrophages in humanized CSF-1 mice. Blood. 2011;118(11):3119-28.

19. Rongvaux A, Willinger T, Martinek J, Strowig T, Gearty SV, Teichmann LL, et al. Development and function of human innate immune cells in a humanized mouse model. Nat Biotechnol. 2014;32(4):364-72.

20. Abud EM, Ramirez RN, Martinez ES, Healy LM, Nguyen CHH, Newman SA, et al. iPSC-derived human microglia-like cells to study neurological diseases. Neuron. 2017:94(2):278-93 e9.

21. Willinger T, Rongvaux A, Takizawa $H$, Yancopoulos GD, Valenzuela DM Murphy AJ, et al. Human IL-3/GM-CSF knock-in mice support human alveolar macrophage development and human immune responses in the lung. Proc Natl Acad Sci U S A. 2011;108(6):2390-5.

22. Borjabad A, Brooks Al, Volsky DJ. Gene expression profiles of HIV-1-infected glia and brain: toward better understanding of the role of astrocytes in HIV1-associated neurocognitive disorders. J Neurolmmune Pharmacol. 2010; 5(1):44-62.

23. Polyak MJ, Vivithanaporn P, Maingat FG, Walsh JG, Branton W, Cohen EA, et al. Differential type 1 interferon-regulated gene expression in the brain during AIDS: interactions with viral diversity and neurovirulence. FASEB J. 2013;27(7):2829-44.

24. Sanna PP, Repunte-Canonigo V, Masliah E, Lefebvre C. Gene expression patterns associated with neurological disease in human HIV infection. PLoS One. 2017;12(4):e0175316.

25. de Vree PJ, de Wit E, Yilmaz M, van de Heijning M, Klous P, Verstegen MJ, et al. Targeted sequencing by proximity ligation for comprehensive variant detection and local haplotyping. Nat Biotechnol. 2014;32(10):1019-25.

26. Gendelman HE, Orenstein JM, Martin MA, Ferrua C, Mitra R, Phipps T, et al. Efficient isolation and propagation of human immunodeficiency virus on recombinant colony-stimulating factor 1-treated monocytes. J Exp Med. 1988;167(4):1428-41.

27. Gorantla S, Makarov E, Finke-Dwyer J, Gebhart CL, Domm W, Dewhurst S, et al. CD8+ cell depletion accelerates HIV-1 immunopathology in humanized mice. J Immunol. 2010;184(12):7082-91.

28. Arainga M, Su H, Poluektova LY, Gorantla S, Gendelman HE. HIV-1 cellular and tissue replication patterns in infected humanized mice. Sci Rep. 2016;6: 23513.

29. Huey DD, Niewiesk S. Production of humanized mice through stem cell transfer. Curr Protoc Mouse Biol. 2018;8(1):17-27.

30. Shultz LD, Saito Y, Najima Y, Tanaka S, Ochi T, Tomizawa M, et al. Generation of functional human T-cell subsets with HLA-restricted immune responses in HLA class I expressing NOD/SCID/IL2r gamma(null) humanized mice. Proc Natl Acad Sci U S A. 2010;107(29):13022-7.

31. Scholbach J, Schulz A, Westphal F, Egger D, Wege AK, Patties I, et al. Comparison of hematopoietic stem cells derived from fresh and cryopreserved whole cord blood in the generation of humanized mice. PLoS One. 2012;7(10):e46772.

32. Cheng L, Ma J, Li G, Su L. Humanized mice engrafted with human HSC only or HSC and Thymus support comparable HIV-1 replication, immunopathology, and responses to ART and Immune therapy. Front Immunol. 2018;9:817.

33. Bade AN, Gorantla S, Dash PK, Makarov E, Sajja BR, Poluektova LY, et al. Manganese-enhanced magnetic resonance imaging reflects brain pathology during progressive HIV-1 infection of humanized mice. Mol Neurobiol. 2016; 53(5):3286-97.

34. Butovsky O, Jedrychowski MP, Moore CS, Cialic R, Lanser AJ, Gabriely G, et al. Identification of a unique TGF-beta-dependent molecular and functional signature in microglia. Nat Neurosci. 2014;17(1):131-43.

35. Garcia-Mesa Y, Jay TR, Checkley MA, Luttge B, Dobrowolski C, Valadkhan S, et al. Immortalization of primary microglia: a new platform to study HIV regulation in the central nervous system. J Neuro-Oncol. 2017;23(1):47-66.

36. Dash PK, Gendelman HE, Roy U, Balkundi S, Alnouti Y, Mosley RL, et al. Long-acting nanoformulated antiretroviral therapy elicits potent antiretroviral and neuroprotective responses in HIV-1-infected humanized mice. AIDS. 2012;26(17):2135-44.

37. Kawai T, Akira S. Signaling to NF-kappaB by toll-like receptors. Trends Mol Med. 2007;13(11):460-9.

38. Capotondo A, Milazzo R, Politi LS, Quattrini A, Palini A, Plati T, et al. Brain conditioning is instrumental for successful microglia reconstitution following hematopoietic stem cell transplantation. Proc Natl Acad Sci U S A. 2012;109(37):15018-23.
39. Derecki NC, Cronk JC, Kipnis J. The role of microglia in brain maintenance: implications for Rett syndrome. Trends Immunol. 2013;34(3):144-50.

40. Varvel NH, Grathwohl SA, Baumann F, Liebig C, Bosch A, Brawek B, et al. Microglial repopulation model reveals a robust homeostatic process for replacing CNS myeloid cells. Proc Natl Acad Sci U S A. 2012;109(44):18150-5.

41. Cronk JC, Filiano AJ, Louveau A, Marin I, Marsh R, Ji E, et al. Peripherally derived macrophages can engraft the brain independent of irradiation and maintain an identity distinct from microglia. J Exp Med. 2018; 215(6):1627-47

42. Honeycutt JB, Thayer WO, Baker CE, Ribeiro RM, Lada SM, Cao Y, et al. HIV persistence in tissue macrophages of humanized myeloid-only mice during antiretroviral therapy. Nat Med. 2017;23(5):638-43.

43. Llewellyn GN, Alvarez-Carbonell D, Chateau M, Karn J, Cannon PM. HIV-1 infection of microglial cells in a reconstituted humanized mouse model and identification of compounds that selectively reverse HIV latency. J NeuroOncol. 2018;24(2):192-203.

44. Mildner A, Schmidt H, Nitsche M, Merkler D, Hanisch UK, Mack M, et al. Microglia in the adult brain arise from Ly-6ChiCCR2+ monocytes only under defined host conditions. Nat Neurosci. 2007;10(12):1544-53.

45. Priller J, Flugel A, Wehner T, Boentert M, Haas CA, Prinz M, et al. Targeting gene-modified hematopoietic cells to the central nervous system: use of green fluorescent protein uncovers microglial engraftment. Nat Med. 2001; 7(12):1356-61.

46. Asheuer M, Pflumio F, Benhamida S, Dubart-Kupperschmitt A, Fouquet F, Imai $Y$, et al. Human CD34+ cells differentiate into microglia and express recombinant therapeutic protein. Proc Natl Acad Sci U S A. 2004;101(10): 3557-62.

47. Menassa DA, Gomez-Nicola D. Microglial dynamics during human brain development. Front Immunol. 2018;9:1014.

48. Li Q, Barres BA. Microglia and macrophages in brain homeostasis and disease. Nat Rev Immunol. 2018;18(4):225-42.

49. Goldmann $T$, Wieghofer $P$, Jordao MJ, Prutek F, Hagemeyer N, Frenzel K, et al. Origin, fate and dynamics of macrophages at central nervous system interfaces. Nat Immunol. 2016;17(7):797-805.

50. Ginhoux F, Garel S. The mysterious origins of microglia. Nat Neurosci. 2018; 21(7):897-9.

51. Prinz M, Erny D, Hagemeyer N. Ontogeny and homeostasis of CNS myeloid cells. Nat Immunol. 2017;18(4):385-92.

52. Capotondo A, Milazzo R, Garcia-Manteiga JM, Cavalca E, Montepeloso A, Garrison BS, et al. Intracerebroventricular delivery of hematopoietic progenitors results in rapid and robust engraftment of microglia-like cells. Sci Adv. 2017;3(12):e1701211.

53. Bennett FC, Bennett ML, Yaqoob F, Mulinyawe SB, Grant GA, Hayden Gephart M, et al. A combination of ontogeny and CNS environment establishes microglial identity. Neuron. 2018;98(6):1170-83 e8.

54. Derecki NC, Cronk JC, Lu Z, Xu E, Abbott SB, Guyenet PG, et al. Wild-type microglia arrest pathology in a mouse model of Rett syndrome. Nature. 2012:484(7392):105-9.

55. Huang Y, Xu Z, Xiong S, Sun F, Qin G, Hu G, et al. Repopulated microglia are solely derived from the proliferation of residual microglia after acute depletion. Nat Neurosci. 2018;21(4):530-40.

56. Mosser CA, Baptista S, Arnoux I, Audinat E. Microglia in CNS development: Shaping the brain for the future. Prog Neurobiol. 2017;149-150:1-20.

57. Nandi S, Cioce M, Yeung YG, Nieves E, Tesfa L, Lin H, et al. Receptor-type protein-tyrosine phosphatase zeta is a functional receptor for interleukin-34. J Biol Chem. 2013;288(30):21972-86.

58. Lawson LJ, Perry VH, Dri P, Gordon S. Heterogeneity in the distribution and morphology of microglia in the normal adult mouse brain. Neuroscience. 1990;39(1):151-70.

59. Walker FR, Beynon SB, Jones KA, Zhao Z, Kongsui R, Cairns M, et al. Dynamic structural remodelling of microglia in health and disease: a review of the models, the signals and the mechanisms. Brain Behav Immun. 2014;37:1-14.

60. Mittelbronn M, Dietz K, Schluesener HJ, Meyermann R. Local distribution of microglia in the normal adult human central nervous system differs by up to one order of magnitude. Acta Neuropathol. 2001;101(3):249-55.

61. Ibeh BO, Furuta Y, Habu JB, Ogbadu L. Humanized mouse as an appropriate model for accelerated global HIV research and vaccine development: current trend. Immunopharmacol Immunotoxicol. 2016; 38(6):395-407.

62. Victor GJ. Humanized mice for HIV and AIDS research. Curr Opin Virol. 2016; 19:56-64. 
63. Honeycutt JB, Garcia JV. Humanized mice: models for evaluating NeuroHIV and cure strategies. J Neuro-Oncol. 2018;24(2):185-91.

64. Gorantla S, Gendelman HE, Poluektova LY. Can humanized mice reflect the complex pathobiology of HIV-associated neurocognitive disorders? J Neurolmmune Pharmacol. 2012;7(2):352-62.

65. Poluektova LY, Epstein AA, Gorantla S. Brain HIV-1 infection modeling in humanized mice. In: Poluektova LY, Garcia JV, Koyanagi Y, Manz MG and Tager AM, editors. Humanized mice for HIV research. New York: Springer; 2014. p. 305-312.

66. Jaeger LB, Nath A. Modeling HIV-associated neurocognitive disorders in mice: new approaches in the changing face of HIV neuropathogenesis. Dis Model Mech. 2012;5(3):313-22.

67. Paquin-Proulx D, Greenspun BC, Kitchen SM, Saraiva Raposo RA, Nixon DF, Grayfer L. Human interleukin-34-derived macrophages have increased resistance to HIV-1 infection. Cytokine. 2018;111:272-7.

68. Gerngross L, Fischer T. Evidence for CFMS signaling in HIV production by brain macrophages and microglia. J Neuro-Oncol. 2015;21(3):249-56.

69. Gerngross L, Lehmicke G, Belkadi A, Fischer T. Role for cFMS in maintaining alternative macrophage polarization in SIV infection: implications for HIV neuropathogenesis. J Neuroinflammation. 2015;12:58.

70. Kure K, Weidenheim KM, Lyman WD, Dickson DW. Morphology and distribution of HIV-1 gp41-positive microglia in subacute AIDS encephalitis. Pattern of involvement resembling a multisystem degeneration. Acta Neuropathol. 1990;80(4):393-400.

71. Ge Y, Kolson DL, Babb JS, Mannon L, Grossman RI. Whole brain imaging of HIV-infected patients: quantitative analysis of magnetization transfer ratio histogram and fractional brain volume. AJNR Am J Neuroradiol. 2003;24(1):82-7.

72. Kieburtz K, Ketonen L, Cox C, Grossman H, Holloway R, Booth H, et al. Cognitive performance and regional brain volume in human immunodeficiency virus type 1 infection. Arch Neurol. 1996;53(2):155-8.

73. Aylward EH, Henderer JD, MCArthur JC, Brettschneider PD, Harris GJ, Barta PE, et al. Reduced basal ganglia volume in HIV-1-associated dementia: results from quantitative neuroimaging. Neurology. 1993;43(10):2099-104.

74. Aylward EH, Brettschneider PD, McArthur JC, Harris GJ, Schlaepfer TE, Henderer $J \mathrm{D}$, et al. Magnetic resonance imaging measurement of gray matter volume reductions in HIV dementia. Am J Psychiatry. 1995;152(7):987-94.

75. Mueller C, Temmel AF, Quint C, Rieger A, Hummel T. Olfactory function in HIV-positive subjects. Acta Otolaryngol. 2002;122(1):67-71.

76. Westervelt HJ, McCaffrey RJ, Cousins JP, Wagle WA, Haase RF. Longitudinal analysis of olfactory deficits in HIV infection. Arch Clin Neuropsychol. 1997; 12(6):557-65.

77. Zucco GM, Ingegneri G. Olfactory deficits in HIV-infected patients with and without AIDS dementia complex. Physiol Behav. 2004;80(5):669-74.

78. Bajramovic JJ. Regulation of innate immune responses in the central nervous system. CNS Neurol Disord Drug Targets. 2011;10(1):4-24.

79. Barichello T, Generoso JS, Goularte JA, Collodel A, Pitcher MR, Simoes LR, et al. Does infection-induced immune activation contribute to dementia? Aging Dis. 2015;6(5):342-8.

80. Lee H, Lee $\mathrm{S}$, Cho $H$, Lee SJ. Toll-like receptors: sensor molecules for detecting damage to the nervous system. Curr Protein Pept Sci. 2013;14(1):33-42.

81. Verma R, Bharti K. Toll like receptor 3 and viral infections of nervous system. J Neurol Sci. 2017;372:40-8

82. Gelman BB, Chen T, Lisinicchia JG, Soukup VM, Carmical JR, Starkey JM, et al. The national NeuroAIDS tissue consortium brain gene array: two types of HIV-associated neurocognitive impairment. PLoS One. 2012;7(9):e46178.

83. Cserhati MF, Pandey S, Beaudoin JJ, Baccaglini L, Guda C, Fox HS. The National NeuroAIDS Tissue Consortium (NNTC) Database: an integrated database for HIV-related studies. Database (Oxford). 2015;2015:bav074.

84. Siangphoe U, Archer KJ. Gene expression in HIV-associated neurocognitive disorders: a meta-analysis. J Acquir Immune Defic Syndr. 2015;70(5):479-88.

85. Winkler JM, Chaudhuri AD, Fox HS. Translating the brain transcriptome in neuroAIDS: from non-human primates to humans. J Neurolmmune Pharmacol. 2012;7(2):372-9.

86. Hidalgo L, Swanson CM. Regulation of human immunodeficiency virus type 1 (HIV-1) mRNA translation. Biochem Soc Trans. 2017;45(2):353-64

87. Endo-Munoz L, Warby T, Harrich D, McMillan NA. Phosphorylation of HIV tat by PKR increases interaction with TAR RNA and enhances transcription. Virol J. 2005:2:17.

88. Chang RC, Yu MS, Lai CS. Significance of molecular signaling for protein translation control in neurodegenerative diseases. Neurosignals. 2006;15(5): 249-58.

\section{Ready to submit your research? Choose BMC and benefit from:}

- fast, convenient online submission

- thorough peer review by experienced researchers in your field

- rapid publication on acceptance

- support for research data, including large and complex data types

- gold Open Access which fosters wider collaboration and increased citations

- maximum visibility for your research: over $100 \mathrm{M}$ website views per year

At BMC, research is always in progress.

Learn more biomedcentral.com/submissions 